\title{
A PERCEPÇÃO DE UM IDOSO SOBRE QUALIDADE DE VIDA E A MORTE
}

Débora Muck Spindler; FACCAT-Faculdades Integradas de Taqura; deboramuck@gmail.com Cristiane Moro dos Santos; FACCAT-Faculdades Integradas de Taquara; cristianesantos@faccat.br

\section{RESUMO}

Pensar no crescente envelhecimento da população, contribuindo em aspectos a conhecer e melhorar a qualidade de vida e a respectiva percepção da morte destes idosos, pode ser uma estratégia para qualificar os anos a mais que temos de vida. $\mathrm{O}$ objetivo deste trabalho foi verificar qual a percepção de um idoso residente na cidade de Taquara/RS, que já adentrou a chamada fase da velhice, sobre a qualidade de vida nesta faixa etária e em questões respectivas à morte, visando também verificar quais os principais fatores biopsicossociais que se fazem importantes neste processo. $\mathrm{O}$ método de pesquisa utilizado foi o qualitativo, na modalidade de caso único instrumental. A coleta de dados foi realizada mediante assinatura do TCLE (Termo de Consentimento Livre Esclarecido), posterior a isto foi aplicado o MEEM (Mini Exame do Estado Mental), para fins de rastreio cognitivo, e após averiguação de comprometimento cognitivo, foram aplicados as escalas Whoqol Old, GDS, e realizada uma entrevista semiestruturada. Os resultados do estudo mostraram que a participante possui qualidade de vida, evidenciada pelos resultados da Escala de Qualidade de Vida Whoqol-Old, e revelou que o principal aspecto biopsicossocial a refletir em sua qualidade de vida são os fatores sociais. A vivência da religiosidade e espiritualidade também aparece como forte aspecto refletindo na qualidade de vida e na respectiva percepção da morte que a participante apresenta, bem como contribuindo na sua visão de envelhecimento, e modo como vive a vida.

Palavras-chave: Idosos; Qualidade de vida; Envelhecimento. 